\title{
Transcriptional activators and activation mechanisms
}

\author{
Jun Ma网 \\ Division of Biomedical Informatics, Division of Developmental Biology, Cincinnati Children's Research Foundation, University of \\ Cincinnati College of Medicine, Cincinnati, OH 45229, USA \\ $\bowtie$ Correspondence: jun.ma@cchmc.org \\ Received July 11, 2011 Accepted August 22, 2011
}

\begin{abstract}
Transcriptional activators are required to turn on the expression of genes in a eukaryotic cell. Activators bound to the enhancer can facilitate either the recruitment of RNA polymerase II to the promoter or its elongation. This article examines a few selected issues in understanding activator functions and activation mechanisms.
\end{abstract}

KEYWORDS activator, transcription, co-activator, enhancer, promoter, signal transduction, development

\section{INTRODUCTION}

Transcription is the process of copying (transcribing) the information from one strand of DNA into RNA by the enzyme called RNA polymerase (RNAP). In bacteria there is only one type of RNAP, but in eukaryotes there are three different types of RNAPs that transcribe different classes of genes (Hahn, 2004). RNAPII is responsible for transcribing protein-coding genes, whereas RNAPI and III are responsible for synthesizing rRNA and tRNA, respectively. Here we focus on transcription by RNAPII (referred to as RNAP from now on), which has been subject to intensive investigations (Kadonaga, 2004; Sims et al., 2004b; Malik and Roeder, 2010; Weake and Workman, 2010; Nechaev and Adelman, 2011). We will discuss mechanisms leading to increased levels of transcription, a process called activation.

In addition to the coding sequence, a typical class II gene contains at least two other types of DNA sequences that are required for initiating transcription. Promoters (also referred to as the core promoters), which are DNA sequences located upstream of the coding regions of the genes, help orient RNAP so that it "knows" where on DNA to start transcribing and in which direction. RNAP itself does not have the ability to recognize specific DNA sequences including the promoter sequences. Instead, a group of proteins, called general transcription factors (GTFs), help RNAP to find promoter sequences (Orphanides et al., 1996; Hampsey, 1998; Nechaev and Adelman, 2011). One of these GTFs is the TATA-box binding protein (TBP), which directly binds to the TATA sequence of the promoter. The protein complex assembled at the promoter is often referred to as the preinitiation complex or transcription machinery (or apparatus). This complex contains GTFs and RNAP. It also contains co-factors and chromatin modifying/remodeling factors that are part of the RNAP holoenzyme. Many of these additional factors play important roles in mediating transcription regulation by responding to regulatory proteins (Naar et al., 2001; Narlikar et al., 2002; Levine and Tjian, 2003; Malik and Roeder, 2000, 2010; Weake and Workman, 2010).

The second type of DNA elements required for initiating gene transcription is the regulatory elements, to which regulatory proteins bind. The elements that play positive roles in transcription are called upstream activation sequences (UASs) in yeast and enhancers in higher eukaryotes such as humans. These sequences (as well as the proximal-promoter elements) provide the binding sites for transcriptional activators that increase the levels of gene transcription. Genes in eukaryotic cells tend to stay inactive (off) unless they are specifically turned on by activators. This is obvious for genes that need to be turned on at precise times and locations in response to environmental or developmental signals. But this is also true for "housekeeping" genes that are transcribed ubiquitously; for these genes, their transcription is also dependent on the action of activators. Many enhancers are located upstream of the genes, but they have also been found in introns or even downstream of the genes (Blackwood and Kadonaga, 1998). Recent studies suggest 
that, in addition to the primary enhancers, genes may also contain secondary, "shadow" enhancers (below). In addition, enhancers often contain binding sites for both activators and repressors to achieve the precise spatial and temporal patterns of gene transcription. Here we focus on activation mechanisms. We first discuss how a typical activator looks like and how it might activate transcription, followed by brief discussions of a few selected issues relevant to understanding activation mechanisms.

\section{A TYPICAL TRANSCRIPTIONAL ACTIVATOR}

A typical activator has two essential functions: DNA binding and transcriptional activation (Ptashne, 1988). The finding that these two functions of an activator are provided by two separable domains led to the suggestion that DNA binding per se was insufficient, though necessary, for activation (Brent, 2004; Brent and Ptashne, 1985; Keegan et al., 1986; Ptashne, 2004). According to our current understanding, the DNA binding domain of an activator provides the specificity for its action (in terms of which gene to activate), whereas its activation domain is responsible for stimulating transcription.

There are different families of DNA binding domains that form distinct three-dimensional (3-D) structures for DNA recognition (Garvie and Wolberger, 2001). These domains tend to bear names that depict their structural and/or functional properties or follow their founding members' names. For example, a zinc-finger DNA binding domain uses zinc to maintain its 3-D structure required for DNA recognition. A basic region-leucine zipper (bZIP) domain contains a basic region (that contacts DNA) and a leucine zipper (that forms dimers). A homeodomain is a conserved 60-aa DNA binding domain initially identified in proteins encoded by Drosophila homeotic genes. A Rel homology domain is a DNA binding domain that bears the name of its founding member Rel. These DNA binding domains, and many others, recognize short, specific DNA sequences by making elaborate contacts with the bases in the major groove of the DNA double helix (Patikoglou and Burley, 1997; Garvie and Wolberger, 2001; Baird-Titus et al., 2006). Some, e.g., the high-mobility-group (HMG) domain, recognize DNA sequences by interacting with the minor groove (Travers, 2000) [The GTF TBP also binds to the TATA sequences by making contacts with the minor groove (Nikolov et al., 1992; Kim et al., 1993)]. Many activators can bind DNA sequences cooperatively with one another, which can increase the stability of the protein complexes formed at the enhancers (Adams and Workman, 1995; Ma et al., 1996).

Unlike DNA binding domains that require elaborate structures for DNA recognition, activation domains tend to be short protein sequences often with very limited sequence complexity (Hope and Struhl, 1986; Ma and Ptashne, 1987a, 1987b). There are different types of activation domains, which are named after their sequence characteristics, such as acidic, glutamine-rich, proline-rich, and alanine-rich. For the acidic class of activating sequences, it was estimated that $1 \%$ of the peptides encoded by random DNA sequences (from the E. coli genome) can activate transcription when fused to a DNA binding domain (Ma and Ptashne, 1987a). This finding further highlights the "relaxed" specificity between activation sequences and their target proteins (Ma, 2004), a feature that stands in contrast to the interaction mode between the DNA binding domains and their recognized DNA sites.

\section{THE RECRUITMENT MODEL}

What does an activator do to stimulate transcription? According to a well-established recruitment model, the ultimate goal of an activator bound at the enhancer is to bring the transcription machinery, in particular RNAP, to the promoter (Stargell and Struhl, 1996; Ptashne and Gann, 1997). Several lines of evidence suggest that recruitment is an important mechanism for transcriptional activation. First, for many genes, the GTFs and RNAP are absent from their promoters unless the genes are turned on by activators (Klein and Struhl, 1994; Chatterjee and Struhl, 1995; Li et al., 1999). Second, activation domains can interact with a wide array of target proteins, many of which are components of the transcription machinery, including the GTFs (e.g., TBP, TFIIB, TFIIE, and TAFs), co-factors and chromatin modifying/remodeling complexes (Ptashne and Gann, 1990; Orphanides et al., 1996; Malik and Roeder, 2000; Peterson and Workman, 2000; Naar et al., 2001; Narlikar et al., 2002). Finally, in a series of "artificial recruitment" experiments that provided pivotal support to this model, it was shown that transcription can be elicited by artificially attaching components of the transcription machinery to a DNA binding domain (Chatterjee and Struhl, 1995; Xiao et al., 1995; Farrell et al., 1996; Gonzalez-Gouto et al., 1997; Nevado et al., 1999). In such an artificial recruitment setup, the requirement for a classical activator is completely bypassed. Instead, "activation" is now achieved through a shortcut mechanism, where the transcription machinery is directly brought to its action site, the promoter, by a covalently-attached DNA binding domain. As discussed below, increasing evidence suggests that transcriptional activation for many genes may take place at a step(s) after recruitment.

\section{COMPOSITE ACTIVATORS}

Although a typical activator contains both an activation domain and a DNA binding domain, sometimes these two domains can reside on separate proteins. For example, the herpes simplex virus (HSV) activator VP16 does not bind to DNA, but rather, it is brought to DNA by interacting with other DNA-bound proteins (Triezenberg et al., 1988). The activation domain of VP16 can also activate transcription when directly 
attached to a DNA binding domain (Sadowski et al., 1988). This finding demonstrated that an activation domain can be brought to DNA by distinct, but interchangeable, means, either directly binding to DNA (through its linked DNA binding domain) or interacting with other DNA-bound proteins. This concept was further demonstrated by the creation of an artificial composite activator (Ma and Ptashne, 1988) and led to the proposal of the yeast two-hybrid system (Fields and Song, 1989).

Transcriptional activators that do not themselves bind DNA but interact with other DNA-bound proteins are often referred to as co-activators. But it is useful to make a distinction between these non-DNA binding activators and the "true" coactivators that play more general roles in transcription (see below). Unlike non-DNA binding activators, which are genespecific (e.g., the Notch intracellular domain), co-activators of the latter class (e.g., CBP and chromatin remodeling complexes) play important roles in mediating the actions of many activators (Ma, 2005). Some of these general, "true" coactivators are components of the RNAP holoenzyme (Ranish and Hahn, 1996; Myers and Kornberg, 2000).

\section{CONFORMATIONAL CHANGES}

The artificial recruitment experiments mentioned above support the notion that, for the genes tested, the ultimate and only function of activators is to bring RNAP to the promoter. It is known that the preinitiation complex undergoes several conformational changes before RNAP actually initiates transcription (Carey and Smale, 2000; Hirose and Ohkuma, 2007). For example, the promoter DNA is significantly bent and unwound upon TBP binding (Nikolov et al., 1992; Kim et al., 1993). In addition, the DNA double helix at the transcription start site becomes unpaired, or melted, to form a bubble prior to transcription initiation by RNAP (Wang et al., 1992; Giardina and Lis, 1993). In one study, it was shown that activators can change the conformation of the TFIIA-TFIID-TATA complex and such a conformational change is necessary and sufficient for activation in an in vitro system (Chi and Carey, 1996). Thus, conformational changes of the transcription machinery represent potential steps that can also be targeted by transcriptional activators.

\section{PROMOTER CLEARANCE AND RELEASE OF PAUSED RNAP}

The largest subunit of RNAP contains a tail-like structure known as the C-terminal domain (CTD), which is composed of heptapeptide repeats with a consensus of YSPTSPS (Meinhart et al., 2005). The number of heptapeptide repeats differs in different species; human RNAP has 52 such repeats whereas yeast RNAP has 26 . The CTD, which is required for cell viability (Nonet et al., 1987), plays a critical role not only in transcription but also in RNA processing and chromatin regulation (Hirose and Ohkuma, 2007). Heptapeptide repeats are subject to extensive phosphorylation. Importantly, the phosphorylation status and specificity exhibit dynamic changes as a function of the transcription cycle, reflective of the balanced action of site-specific kinases and phosphatases (Meinhart et al., 2005). During preinitiation complex formation, the CTD is un-phosphorylated. It becomes phosphorylated at serine 5 (Ser5) when RNAP transitions from initiation to elongation, refereed to as promoter clearance or escape (Hirose and Ohkuma, 2007; Levine, 2011). This transition allows RNAP to gain competence to transcribe into the main body of the gene (Levine, 2011). Thus, promoter clearance represents an important step toward productive gene transcription. It has been suggested that Ser5 phosphorylation, catalyzed by the Cdk7 kinase in the TFIIH complex and the Cdk8 kinase in the mediator complex, may itself be responsible for this transition (Hirose and Ohkuma, 2007). As RNAP transcribes into the main body of the gene, its CTD becomes phosphorylated at serine 2 (see below).

It is well documented that, prior to the induction of some genes, RNAP is already engaged at their $5^{\prime}$ regions (after promoter clearance) but it becomes "stalled" or paused near the promoters (Rougvie and Lis, 1988; Krumm et al., 1992; Rasmussen and Lis, 1993, 1995; Levine, 2011). For these genes, which are referred to as having a "preloaded" RNAP, transcriptional activation must take place at a step(s) after RNAP recruitment and transcription initiation. Activation for these genes is thus a process of enabling the paused RNAP to elongate, i.e., to transcribe productively through the genes' entire lengths. This process is referred to as the release of paused RNAP from the proximal promoter (Levine, 2011; Li and Gilmour, 2011; Nechaev and Adelman, 2011). Recent genome-wide studies have revealed that a significant fraction of genes have stalled RNAP near their promoters (Zeitlinger et al., 2007; Core et al., 2008; Nechaev et al., 2010). In addition, mutation of the polycomb group gene extra sex combs (esc) can cause an increased occupancy of RNAP at many genes, suggesting that the promoter type (with regard to the presence of preloaded RNAP) is sensitive to chromatin structure (Chopra et al., 2011). It has been suggested that promoters with preloaded RNAP can respond to activation signals more "quickly" and uniformly (Boettiger and Levine, 2009). In addition, paused RNAP has been suggested to provide a checkpoint to ensure a successful coupling between transcription and mRNA processing or to prevent "mistakes" during the transcription process (Sims et al., 2004a; Levine, 2011).

Many proteins (or complexes) have been identified that play important roles in facilitating transcription elongation, and some of these factors represent targets for activators (Sims et al., 2004a; Peterlin and Price, 2006). For example, experiments in Drosophila suggested that the elongation 
factor P-TEFb is recruited to the heat shock loci to facilitate transcription elongation upon heat shock induction (Lis et al., 2000). The HIV Tat activator has also been suggested to stimulate transcription elongation by recruiting the elongation factor P-TEFb (Mancebo et al., 1997; Zhu et al., 1997; Zhou et al., 1998). P-TEFb is a protein complex that contains the Cdk9 kinase, which may directly phosphorylate Ser2 in the CTD thus facilitating the release of paused RNAP from the proximal promoter (Peterlin and Price, 2006; Levine, 2011). In addition, in vitro experiments using the human $h s p 70$ gene demonstrated that the SWI/SNF chromatin remodeling complex was recruited by the human activator HSF1 to facilitate transcription elongation (Brown et al., 1996). These examples highlight the importance of the elongation step in transcriptional activation (Levine, 2011; Li and Gilmour, 2011; Nechaev and Adelman, 2011).

\section{CHROMATIN REMODELING AND MODIFICATIONS}

A major difference between eukaryotes and prokaryotes is that eukaryotic DNA is packaged into nucleosomes ( $\mathrm{Li}$ et al., 2007; Ho and Crabtree, 2010). Nucleosomes can impede DNA binding of transcription factors and GTFs and form a transcriptional barrier for RNAP. Thus, chromatin structure can significantly reduce the efficiency of transcription at both the initiation and elongation steps (Wu, 1997; Peterson and Workman, 2000; Wu and Grunstein, 2000; Narlikar et al., 2002; Li et al., 2007). It is well established that genes can be de-repressed when histones are depleted from cells (Han and Grunstein, 1988). A genome-wide analysis revealed that $15 \%$ of the yeast genes had a de-repressed (increased) expression upon the removal of histone H4 (Wyrick et al., 1999).

The role of chromatin structure in transcriptional activation has been subject to intensive mechanistic investigations (Li et al., 2007). These studies reveal two broad mechanisms that can lessen the repressive effects of chromatin structure. The first mechanism involves chromatin remodeling, a process where the contacts between histones and DNA are altered by ATP-dependent chromatin remodeling complexes ( $\mathrm{Li}$ et al., 2007; Ho and Crabtree, 2010). These complexes are divided into four main families based on the sequence of the ATPase subunit, SWI/SNF, ISWI, CHD, and INO80 complexes (Ho and Crabtree, 2010). These complexes utilize ATP as energy to induce a variety of changes that increase the accessibility of nucleasomal DNA to transcription factors and GTFs and weaken the transcriptional barrier, thus leading to more efficient transcription initiation or elongation ( $\mathrm{Li}$ et al., 2007; Ho and Crabtree, 2010).

The second mechanism involves posttranslational modifications of histone (Kouzarides, 2007; Li et al., 2007; Ruthenburg et al., 2007; Bannister and Kouzarides, 2011). Histones have flexible, unstructured $\mathrm{N}$-terminal tails that are subject to a variety of posttranslational modifications, including acetylation, phosphorylation, methylation and ubiquitination (Kouzarides, 2007; Li et al., 2007; Ruthenburg et al., 2007; Bannister and Kouzarides, 2011). It is thought that many of these modifications, in particular acetylation, can reduce the net positive charge of nucleosomes, thus loosening their interactions with DNA and increasing the efficiency of transcription initiation or elongation (Li et al., 2007). Posttranslational modifications of histones can also provide recognition platforms for other factors, referred to as the effector proteins, that further define the functional outcome of a modification in transcription (Li et al., 2007; Ruthenburg et al., 2007). It is noted that, since most of the chromatin remodeling complexes and histone modifying enzymes cannot bind specific DNA sequences, they are brought to the specific targets (genes) by transcriptional activators. They are thus referred to as transcriptional co-factors and, for those with a positive role in transcription, as co-activators (see above).

\section{SYNERGISM}

One of the characteristic features of transcriptional activation is synergism. Synergy refers to the situation where the transcription level achieved by multiple activators is higher than the sum of the levels by individual factors separately. Synergy can arise from different mechanisms. In the simplest case, it can be due to cooperative binding of activators to multiple sites in the enhancer (Adams and Workman, 1995; Ma et al., 1996; Burz et al., 1998). This is true if the activators are at limiting (sub-saturating) concentrations. An enhanceosome model has been proposed that further emphasizes the role of multiple activators for activation (Thanos and Maniatis, 1995; Merika and Thanos, 2001). According to this model, different activators, including those that play architectural roles, are together required to form a stable complex at the enhancer for efficient transcriptional activation. Synergy can also be achieved even when activators are at saturating levels, suggesting that activators may contact multiple targets in the transcription machinery (Ptashne and Gann, 1998).

Studies to compare the roles of different activators suggest that synergy may reflect combinatorial actions on distinct steps of transcription (Blau et al., 1996). By comparing the RNAP density along a gene, it is possible to gain information about which step, initiation or elongation, an activator may stimulate. Using this and other analyses, Blau et al. (Blau et al., 1996) concluded that, while some activators (e.g., Sp1 and CTF) work primarily on the initiation step, others (e.g., Tat) work primarily on the elongation step. Another class of activators (e.g., VP16, p53 and E2F1) can work on both initiation and elongation. An analysis of these activators revealed that synergy was only achieved between those that work on different steps of transcription (Blau et al., 1996). 


\section{ACTIVATOR-REPRESSOR SWITCHES}

Transcription factors can often work as either activators or repressors in a context-dependent manner (Ma, 2005; Bauer et al., 2010). For example, many transcription factors that mediate signal transduction processes function as repressors in the absence of the signals but as activators in the presence of the signals. In addition, the concentrations and posttranslational modifications of a transcription factor can affect its ability to either activate or repress transcription. The presence of other nearby DNA binding proteins on DNA, as well as the availability and concentration of co-factors, can also influence the behavior of a transcription factor. Thus, understanding the precise role of a transcription factor in regulating the expression of a target gene requires the knowledge about the context in which it operates (Ma, 2005; Bauer et al., 2010).

\section{ACTIVATOR MODIFICATIONS}

Similar to histones, activators are also subject to a variety of posttranslational modifications, such as phosphorylation (Brivanlou and Darnell, 2002), acetylation (Brooks and Gu, 2003), and glycosylation (Jackson and Tjian, 1988; Kamemura and Hart, 2003). In many cases the posttranslational modifications can have positive roles in transcriptional activation. For example, phosphorylation of transducer and activator of transcription (STAT) is responsible for mediating the JAK/STAT signal transduction pathway (Darnell et al., 1994; Brivanlou and Darnell, 2002). Acetylation of p53 can increase its ability to bind DNA (Gu and Roeder, 1997; Prives and Manley, 2001; Brooks and Gu, 2003). Recent studies suggest that ubiquitination and sumoylation also play important roles in regulating the activity of transcription factors (Conaway et al., 2002; Herrera and Triezenberg, 2004; Gill, 2005; Ouyang and Gill, 2009; Frappier and Verrijzer, 2011). For many activators, their actions of stimulating transcription are coupled with their ubiquitination-dependent degradation (von der Lehr et al., 2003; Lipford et al., 2005; Muratani et al., 2005; Wu et al., 2007). Such a coupling, which was originally documented for classical activators that have activation domains, also appears to be operative for non-classical activators that do not have activation domains (Wang et al., 2010). Thus, cells have evolved mechanisms to maintain a "fresh" state by quickly eliminating the activator molecules that have fulfilled their duties of stimulating transcription.

\section{SHADOW ENHANCERS}

Recent studies suggest that, in addition to the primary enhancers, genes may also contain secondary enhancers, referred to as shadow enhancers (Hong et al., 2008). The primary enhancer and the shadow enhancer of a gene are often able to direct similar expression patterns. Thus these enhancers have redundant functions. It has been proposed that shadow enhancers can increase the robustness of gene expression (Frankel et al., 2010; Hobert, 2010; Perry et al., 2010). In addition, shadow enhancers may also have facilitated the creation of new regulatory DNA sequences through evolution (Hong et al., 2008).

\section{SHORT DISTANCE VS LONG DISTANCE ACTIONS}

Enhancers in higher eukaryotes have the ability to exert their effects even when they are located many kilobases away from the promoters (Blackwood and Kadonaga, 1998; Wallace and Felsenfeld, 2007; Ong and Corces, 2011). There are no clear-cut definitions of short distance vs long distance, but for our discussion we can consider short distance as anything up to a few hundred base pairs and long distance greater than one kilobase (Blackwood and Kadonaga, 1998; Dorsett, 1999). The mechanisms for activation at short or long distances may be fundamentally similar in that they are both achieved, ultimately, through a network of protein-protein interactions and alterations of chromatin structure. But activation at a long distance (e.g., 50-60 kilobases) faces two additional challenges that are less relevant to activation at a short distance (e.g., 100-200 bp). First, how can promoters and enhancers communicate through such long distances? Second, how does an enhancer "choose" to activate one promoter, but not another one that is also within its reach?

Proteins called facilitators have been proposed to promote the interaction between enhancers and promoters that are separated by long distances (Bulger and Groudine, 1999; Dorsett, 1999). For example, the Drosophila protein called Chip, which can interact with many transcription factors and co-factors (Morcillo et al., 1997; Torigoi et al., 2000; Matthews and Visvader, 2003; Bronstein et al., 2010), has been proposed to play such a role (Dorsett, 1999). In addition, recent studies have revealed critical roles of cohesin and noncoding RNAs in facilitating the communication between enhancers and promoters (Ong and Corces, 2011). The efficiency (and specificity) of the communication between enhancers and promoters can also be augmented by DNA sequences, called tethering elements, which are located near the core promoters (Bertolino and Singh, 2002; Calhoun et al., 2002). For example, the POU domain of Oct-1 bound to DNA sites near a promoter enables the promoter to respond to a distant enhancer (Bertolino and Singh, 2002). Finally, since eukaryotic genomes can have very large (on the scale of $>100$ kilobases) domains that contain genes with similar expression patterns (Spellman and Rubin, 2002), it appears that some higher order control elements may play a role in controlling the genomic landscape of transcription (Calhoun and Levine, 2003; Spitz et al., 2003; Zuniga et al., 2004).

The specificity of long-distance communication between enhancers and promoters can be regulated by different 
mechanisms (Blackwood and Kadonaga, 1998; Wallace and Felsenfeld, 2007). First, the tethering elements mentioned above can selectively facilitate the communication between a promoter and one, but not another, enhancer (Calhoun et al., 2002). Second, in some cases promoters can compete with each other for an enhancer, and thus the enhancer preferentially communicates with the strong promoter, while ignoring the weak promoter (Foley and Engel, 1992; Sharpe et al., 1998). Finally, insulator elements can prevent "unwanted" communications between enhancers and promoters thus encouraging "wanted" interactions; an insulator is a DNA element that can block the communication between an enhancer (or a silencer) and a promoter when the insulator is located between them, but not when it is located outside the enhancer-promoter unit (West et al., 2002; Kuhn and Geyer, 2003; Wallace and Felsenfeld, 2007).

\section{TRANSCRIPTIONAL BURSTS}

Our discussions thus far have intentionally avoided the question of what activation means in terms of the behavior of individual cells or individual copies of genes inside a cell. This is in part because most transcriptional studies measure the accumulated transcription products of many cells from a tissue. In other words, these measured products have already been averaged over many cells and, thus, depict only the "average" behavior of these cells as a group. Recent studies of evaluating the transcriptional products of individual cells suggest that transcription takes place as discrete bursts (Elowitz et al., 2002; Kaern et al., 2005; Raser and O'Shea, 2005; Golding and Cox, 2006; Pare et al., 2009; Chubb and Liverpool, 2010; To and Maheshri, 2010). Transcriptional activators appear to increase the frequency or probability of such bursts, as opposed to the number of transcripts produced per burst (Porcher et al., 2010; To and Maheshri, 2010; He et al., 2011).

Understanding mechanistically how activators work in their native biological systems as a function of both space and time represents an important scientific challenge. The Drosophila activator Bicoid $(\mathrm{Bcd})$ forms a concentration gradient in early embryos and instructs anterior-posterior patterning (Grimm et al., 2010; Lohr et al., 2010; Porcher and Dostatni, 2010; Liu et al., 2011). It offers an excellent system for studying transcriptional activation mechanisms in both space and time (Gregor et al., 2007a, b; He et al., 2008; Deng et al., 2010; He et al., 2010a, b; Porcher et al., 2010; Cheung et al., 2011; Liu and $\mathrm{Ma}, 2011)$. A recently reported method of simultaneously, and quantitatively, detecting Bcd and the nascent transcripts of its target genes in early Drosophila embryos made it possible to evaluate the role of this activator in the actual events of transcriptional bursts, as opposed to the accumulated products (He et al., 2011). Our reported study captured for the first time the action of Bcd in stimulating the actual transcriptional bursts of individual copies of its target genes in a native developmental system. A comparison between the noise in transcriptional products and the noise in transcriptional events documented the effect of time averaging in reducing the noise in transcriptional output (He et al., 2011). Furthermore, a mathematical dissection of the measured noise in transcriptional bursts of Bcd target genes, coupled with the direct measurement of the Bcd activator input noise, has made it possible to evaluate-at a systems levelwhether Bcd acts as a dominant input for its target gene transcription (He et al., in preparation). Finally, an analysis of a narrow time window for transcriptional bursts of a Bcd target gene has led to the demonstration that an important mechanism to control the levels of transcription products is to regulate the size of the transcriptional time window (Liu and $\mathrm{Ma}$, in preparation).

\section{CONCLUDING REMARKS}

I would like to end our discussion by returning to the issue introduced earlier, i.e., a typical activator has two essential functions, DNA binding and activation. Why, then, do activators have to bind DNA, or for non-DNA binding activators, interact with other DNA-bound proteins? This question touches the very heart of the activation process. DNA binding brings an activator closer to the promoter, its action site, thus effectively increasing its local concentration. For an individual copy of a gene inside a cell, activator molecules bound at the enhancer can increase the probability of its transcriptional bursts; the stochastic nature of such bursts could reflect directly the stochastic binding of activator molecules to the enhancer or the stochastic (activator-facilitated) loading of RNAP to the promoter (Golding et al., 2005). For a promoter that is preloaded with RNAP, activator molecules bound at the enhancer can stimulate elongation of the stalled RNAP to achieve a productive transcriptional event. In both cases, activator molecules lead to successful transcriptional events only when they are brought closer to their action site. It should be noted that, while activation is a process of increasing transcription levels, transcription is also subject to repression, a process of reducing its levels. Understanding gene regulation requires considerations of integrating transcriptional activation and repression.

\section{ACKNOWLEDGEMENTS}

I would like to thank members of my lab for discussions and NSF, NIH, $\mathrm{AHA}$ and $\mathrm{CCHMC}$ for supporting our research. This is an update version of a chapter that appeared in Gene Expression and Regulation (2006). Ma J. ed. Beijing: Higher Education Press \& Springer.

\section{ABBREVIATIONS}

CTD, C-terminal domain; GTFs, general transcription factors; RNAP, RNA polymerase; TBP, TATA-box binding protein; UASs, upstream activation sequences 


\section{REFERENCES}

Adams, C.C., and Workman, J.L. (1995). Binding of disparate transcriptional activators to nucleosomal DNA is inherently cooperative. Mol Cell Biol 15, 1405-1421.

Baird-Titus, J.M., Clark-Baldwin, K., Dave, V., Caperelli, C.A., Ma, J., and Rance, M. (2006). The solution structure of the native K50 Bicoid homeodomain bound to the consensus TAATCC DNAbinding site. J Mol Biol 356, 1137-1151.

Bannister, A.J., and Kouzarides, T. (2011). Regulation of chromatin by histone modifications. Cell Res 21, 381-395.

Bauer, D.C., Buske, F.A., and Bailey, T.L. (2010). Dual-functioning transcription factors in the developmental gene network of Drosophila melanogaster. BMC Bioinformatics 11, 366.

Bertolino, E., and Singh, H. (2002). POU/TBP cooperativity: a mechanism for enhancer action from a distance. Mol Cell 10, 397-407.

Blackwood, E.M., and Kadonaga, J.T. (1998). Going the distance: a current view of enhancer action. Science 281, 61-63.

Blau, J., Xiao, H., McCracken, S., O'Hare, P., Greenblatt, J., and Bentley, D. (1996). Three functional classes of transcriptional activation domains. Mol Cell Biol 16, 2044-2055.

Boettiger, A.N., and Levine, M. (2009). Synchronous and stochastic patterns of gene activation in the Drosophila embryo. Science 325, 471-473.

Brent, R. (2004). Building an artificial regulatory system to understand a natural one. Cell 116, S73-74, $71 \mathrm{p}$ following S76.

Brent, R., and Ptashne, M. (1985). A eukaryotic transcriptional activator bearing the DNA specificity of a prokaryotic repressor. Cell 43, 729-736.

Brivanlou, A.H., and Darnell, J.E. Jr. (2002). Signal transduction and the control of gene expression. Science 295, 813-818.

Bronstein, R., Levkovitz, L., Yosef, N., Yanku, M., Ruppin, E., Sharan, R., Westphal, H., Oliver, B., and Segal, D. (2010). Transcriptional regulation by CHIP/LDB complexes. PLoS Genet 6, e1001063.

Brooks, C.L., and Gu, W. (2003). Ubiquitination, phosphorylation and acetylation: the molecular basis for p53 regulation. Curr Opin Cell Biol 15, 164-171.

Brown, S.A., Imbalzano, A.N., and Kingston, R.E. (1996). Activatordependent regulation of transcriptional pausing on nucleosomal templates. Genes Dev 10, 1479-1490.

Bulger, M., and Groudine, M. (1999). Looping versus linking: toward a model for long-distance gene activation. Genes Dev 13, 2465-2477.

Burz, D.S., Pivera-Pomar, R., Jackle, H., and Hanes, S.D. (1998). Cooperative DNA-binding by Bicoid provides a mechanism for threshold-dependent gene activation in the Drosophila embryo. EMBO J 17, 5998-6009.

Calhoun, V.C., and Levine, M. (2003). Coordinate regulation of an extended chromosome domain. Cell 113, 278-280.

Calhoun, V.C., Stathopoulos, A., and Levine, M. (2002). Promoterproximal tethering elements regulate enhancer-promoter specificity in the Drosophila Antennapedia complex. Proc Natl Acad Sci USA 99, 9243-9247.

Carey, M., and Smale, S.T. (2000). Transcriptional regulation in eukaryotes: Concepts, Strategies, and Techniques. Cold Spring Harbor, New York: Cold Spring Harbor Laboratory Press.

Chatterjee, S., and Struhl, K. (1995). Connecting a promoter-bound protein to TBP bypasses the need for a transcriptional activation domain. Nature 374, 820-822.

Cheung, D., Miles, C., Kreitman, M., and Ma, J. (2011). Scaling of the Bicoid morphogen gradient by a volume-dependent production rate. Development 138, 2741-2749.

Chi, T., and Carey, M. (1996). Assembly of the isomerized TFIIATFIID-TATA ternary complex is necessary and sufficient for gene activation. Gend Dev 10, 2540-2550.

Chopra, V.S., Hendrix, D.A., Core, L.J., Tsui, C., Lis, J.T., and Levine, M. (2011). The polycomb group mutant esc leads to augmented levels of paused Pol II in the Drosophila embryo. Mol Cell 42, 837-844.

Chubb, J.R., and Liverpool, T.B. (2010). Bursts and pulses: insights from single cell studies into transcriptional mechanisms. Curr Opin Genet Dev 20, 478-484.

Conaway, R.C., Brower, C.S., and Conaway, J.W. (2002). Emerging roles of ubiquitin in transcription regulation. Science 296, 1254-1258.

Core, L.J., Waterfall, J.J., and Lis, J.T. (2008). Nascent RNA sequencing reveals widespread pausing and divergent initiation at human promoters. Science 322, 1845-1848.

Darnell, J.E., Jr., Kerr, I.M., and Stark, G.R. (1994). Jak-STAT pathways and transcriptional activation in response to IFNs and other extracellular signaling proteins. Science 264, 1415-1421.

Deng, J., Wang, W., Lu, L.J., and Ma, J. (2010). A two-dimensional simulation model of the Bicoid gradient in Drosophila. PLoS ONE 5, e10275.

Dorsett, D. (1999). Distant liaisons: long-range enhancer-promoter interactions in Drosophila. Curr Opin Genet Dev 9, 505-514.

Elowitz, M.B., Levine, A.J., Siggia, E.D., and Swain, P.S. (2002). Stochastic gene expression in a single cell. Science 297, 1183-1186.

Farrell, S., Simkovich, N., Wu, Y., Barberis, A., and Ptashne, M. (1996). Gene activation by recruitment of the RNA polymerase II holoenzyme. Gend Dev 10, 2359-2367.

Fields, S., and Song, O. (1989). A novel genetic system to detect protein-protein interactions. Nature 340, 245-246.

Foley, K.P., and Engel, J.D. (1992). Individual stage selector element mutations lead to reciprocal changes in beta- vs. epsilon-globin gene transcription: genetic confirmation of promoter competition during globin gene switching. Genes Dev 6, 730-744.

Frankel, N., Davis, G.K., Vargas, D., Wang, S., Payre, F., and Stern, D.L. (2010). Phenotypic robustness conferred by apparently redundant transcriptional enhancers. Nature 466, 490-493.

Frappier, L., and Verrijzer, C.P. (2011). Gene expression control by protein deubiquitinases. Curr Opin Genet Dev 21, 207-213.

Garvie, C.W., and Wolberger, C. (2001). Recognition of specific DNA sequences. Mol Cell 8, 937-946.

Giardina, C., and Lis, J.T. (1993). DNA melting on yeast RNA polymerase II promoters. Science 261, 759-762.

Gill, G. (2005). Something about SUMO inhibits transcription. Curr Opin Genet Dev 15, 536-541.

Golding, I., and Cox, E.C. (2006). Eukaryotic transcription: what does it mean for a gene to be 'on'? Curr Biol 16, R371-R373.

Golding, I., Paulsson, J., Zawilski, S.M., and Cox, E.C. (2005). Realtime kinetics of gene activity in individual bacteria. Cell 123, 1025-1036.

Gonzalez-Gouto, E., Klages, N., and Strubin, M. (1997). Synergistic 
and promoter-selective activation of transcription by recruitment of transcription factors TFIID and TFIIB. Proc Natl Acad Sci USA 94, 8036-8041.

Gregor, T., Tank, D.W., Wieschaus, E.F., and Bialek, W. (2007a). Probing the limits to positional information. Cell 130, 153-164.

Gregor, T., Wieschaus, E.F., McGregor, A.P., Bialek, W., and Tank, D. W. (2007b). Stability and nuclear dynamics of the bicoid morphogen gradient. Cell 130, 141-152.

Grimm, O., Coppey, M., and Wieschaus, E. (2010). Modelling the Bicoid gradient. Development 137, 2253-2264.

Gu, W., and Roeder, R.G. (1997). Activation of p53 sequence-specific DNA binding by acetylation of the p53 C-terminal domain. Cell 90, 595-606.

Hahn, S. (2004). Structure and mechanism of the RNA polymerase II transcription machinery. Nat Struct Mol Biol 11, 394- 403.

Hampsey, M. (1998). Molecular Genetics of the RNA polymerase II general transcription machinery. Microbiol Mol Biol Rev 62, 465-503.

Han, M., and Grunstein, M. (1988). Nucleosome loss activates yeast downstream promoters in vivo. Cell 55, 1137-1145.

He, F., Ren, J., Wang, W., and Ma, J. (2011). A multiscale investigation of bicoid-dependent transcriptional events in Drosophila embryos. PLoS ONE 6, e19122.

He, F., Saunders, T., Wen, Y., Cheung, D., Jiao, R., ten Wolde, P., Howard, M., and Ma, J. (2010a). Shaping a morphogen gradient for positional precision. Biophys J 99, 697-707.

He, F., Wen, Y., Cheung, D., Deng, J., Lu, L.J., Jiao, R., and Ma, J. (2010b). Distance measurements via the morphogen gradient of Bicoid in Drosophila embryos. BMC Dev Biol 10, 80.

He, F., Wen, Y., Deng, J., Lin, X., Lu, J., Jiao, R., and Ma, J. (2008). Probing intrinsic properties of a robust morphogen gradient in Drosophila. Dev Cell 15, 558-567.

Herrera, F.J., and Triezenberg, S.J. (2004). Molecular biology: what ubiquitin can do for transcription. Curr Biol 14, R622-R624.

Hirose, Y., and Ohkuma, Y. (2007). Phosphorylation of the C-terminal domain of RNA polymerase II plays central roles in the integrated events of eucaryotic gene expression. J Biochem 141, 601-608.

Ho, L., and Crabtree, G.R. (2010). Chromatin remodelling during development. Nature 463, 474-484.

Hobert, O. (2010). Gene regulation: enhancers stepping out of the shadow. Curr Biol 20, R697-R699.

Hong, J.W., Hendrix, D.A., and Levine, M.S. (2008). Shadow enhancers as a source of evolutionary novelty. Science (New York, NY 321, 1314.

Hope, I.A., and Struhl, K. (1986). Functional dissection of a eukaryotic transcriptional activator protein, GCN4 of yeast. Cell 46, 885-894.

Jackson, S.P., and Tjian, R. (1988). O-glycosylation of eukaryotic transcription factors: implications for mechanisms of transcriptional regulation. Cell 55, 125-133.

Kadonaga, J.T. (2004). Regulation of RNA polymerase II transcription by sequence-specific DNA binding factors. Cell 116, 247-257.

Kaern, M., Elston, T.C., Blake, W.J., and Collins, J.J. (2005). Stochasticity in gene expression: from theories to phenotypes. Nat Rev Genet 6, 451-464.

Kamemura, K., and Hart, G.W. (2003). Dynamic interplay between Oglycosylation and O-phosphorylation of nucleocytoplasmic proteins: a new paradigm for metabolic control of signal transduction and transcription. Prog Nucleic Acid Res Mol Biol 73, 107-136.
Keegan, L., Gill, G., and Ptashne, M. (1986). Separation of DNA binding from the transcriptional-activating function of a eukaryotic regulatory protein. Science 231, 699-704.

Kim, Y., Geiger, J.H., Hahn, S., and Sigler, P.B. (1993). Crystal structure of a yeast TBP/TATA-box complex. Nature 365, 512-520.

Klein, C., and Struhl, K. (1994). Increased recruitment of TATAbinding protein to the promoter by transcriptional activation domains in vivo. Science 266, 280-282.

Kouzarides, T. (2007). Chromatin modifications and their function. Cell 128, 693-705.

Krumm, A., Meulia, T., Brunvand, M., and Groudine, M. (1992). The block to transcriptional elongation within the human c-myc gene is determined in the promoter-proximal region. Gend Dev 6, 2201-2213.

Kuhn, E.J., and Geyer, P.K. (2003). Genomic insulators: connecting properties to mechanism. Curr Opin Cell Biol 15, 259-265.

Levine, M. (2011). Paused RNA polymerase II as a developmental checkpoint. Cell 145, 502-511.

Levine, M., and Tjian, R. (2003). Transcription regulation and animal diversity. Nature 424, 147-151.

Li, B., Carey, M., and Workman, J.L. (2007). The role of chromatin during transcription. Cell 128, 707-719.

Li, J., and Gilmour, D.S. (2011). Promoter proximal pausing and the control of gene expression. Curr Opin Genet Dev 21, 231-235.

Li, X.Y., Virbasius, A., Zhu, X., and Green, M.R. (1999). Enhancement of TBP binding by activators and general transcription factors. Nature 399, 605-609.

Lipford, J.R., Smith, G.T., Chi, Y., and Deshaies, R.J. (2005). A putative stimulatory role for activator turnover in gene expression. Nature 438, 113-116.

Lis, J.T., Mason, P., Peng, J., Price, D.H., and Werner, J. (2000). PTEFb kinase recruitment and function at heat shock loci. Genes Dev 14, 792-803.

Liu, J., He, F., and Ma, J. (2011). Morphogen gradient formation and action: insights from studying Bicoid protein degradation. Fly (Austin) 5, 424-426.

Liu, J., and Ma, J. (2011). Fates-shifted is an F-box protein that targets Bicoid for degradation and regulates developmental fate determination in Drosophila embryos. Nat Cell Biol 13, 22-29.

Lohr, U., Chung, H.R., Beller, M., and Jackle, H. (2010). Bicoid: Morphogen function revisited. Fly (Austin) 4, 236-240.

Ma, J. (2004). Actively seeking activating sequences. Cell S116, S75-S76.

Ma, J. (2005). Crossing the line between activation and repression. Trends Genet 21, 54-59.

Ma, J., and Ptashne, M. (1987a). A new class of yeast transcriptional activators. Cell 51, 113-119. Re-printed in part: Cell, S116 (2004).

Ma, J., and Ptashne, M. (1987b). Deletion analysis of GAL4 defines two transcriptional activating segments. Cell 48, 847-853.

Ma, J., and Ptashne, M. (1988). Converting a eukaryotic transcriptional inhibitor into an activator. Cell 55, 443-446.

Ma, X., Yuan, D., Diepold, K., Scarborough, T., and Ma, J. (1996). The Drosophila morphogenetic protein Bicoid binds DNA cooperatively. Development 122, 1195-1206.

Malik, S., and Roeder, R.G. (2000). Transcriptional regulation through Mediator-like coactivators in yeast and metazoan cells. Trends Biochem Sci 25, 277-283.

Malik, S., and Roeder, R.G. (2010). The metazoan Mediator 
co-activator complex as an integrative hub for transcriptional regulation. Nat Rev Genet 11, 761-772.

Mancebo, H.S., Lee, G., Flygare, J., Tomassini, J., Luu, P., Zhu, Y., Peng, J., Blau, C., Hazuda, D., Price, D., et al. (1997). P-TEFb kinase is required for HIV Tat transcriptional activation in vivo and in vitro. Genes Dev 11, 2633-2644.

Matthews, J.M., and Visvader, J.E. (2003). LIM-domain-binding protein 1: a multifunctional cofactor that interacts with diverse proteins. EMBO Rep 4, 1132-1137.

Meinhart, A., Kamenski, T., Hoeppner, S., Baumli, S., and Cramer, P. (2005). A structural perspective of CTD function. Genes Dev 19, 1401-1415.

Merika, M., and Thanos, D. (2001). Enhanceosomes. Curr Opin Genet Dev 11, 205-208.

Morcillo, P., Rosen, C., Baylies, M.K., and Dorsett, D. (1997). Chip, a widely expressed chromosomal protein required for segmentation and activity of a remote wing margin enhancer in Drosophila. Genes Dev 11, 2729-2740.

Muratani, M., Kung, C., Shokat, K.M., and Tansey, W.P. (2005). The F box protein Dsg1/Mdm30 is a transcriptional coactivator that stimulates Gal4 turnover and cotranscriptional mRNA processing. Cell 120, 887-899.

Myers, L.C., and Kornberg, R.D. (2000). Mediator of transcriptional regulation. Annu Rev Biochem 69, 729-749.

Naar, A.M., Lemon, B.D., and Tjian, R. (2001). Transcriptional coactivator complexes. Annu Rev Biochem 70, 475-501.

Narlikar, G.J., Fan, H.Y., and Kingston, R.E. (2002). Cooperation between complexes that regulate chromatin structure and transcription. Cell 108, 475-487.

Nechaev, S., and Adelman, K. (2011). Pol II waiting in the starting gates: Regulating the transition from transcription initiation into productive elongation. Biochim Biophys Acta 1809, 34- 45.

Nechaev, S., Fargo, D.C., dos Santos, G., Liu, L., Gao, Y., and Adelman, K. (2010). Global analysis of short RNAs reveals widespread promoter-proximal stalling and arrest of Pol II in Drosophila. Science 327, 335-338.

Nevado, J., Gaudreau, L., Adam, M., and Ptashne, M. (1999). Transcriptional activation by artificial recruitment in mammalian cells. Proc Natl Acad Sci USA 96, 2674-2677.

Nikolov, D.B., Hu, S.-H., Lin, J., Gasch, A., Hoffmann, A., Horikoshi, M., Chua, N.-H., Roeder, R.G., and Burley, S.K. (1992). Crystal structure of TFIID TATA-box binding protein. Nature 360, 40-46.

Nonet, M., Sweetser, D., and Young, R.A. (1987). Functional redundancy and structural polymorphism in the large subunit of RNA polymerase II. Cell 50, 909-915.

Ong, C.T., and Corces, V.G. (2011). Enhancer function: new insights into the regulation of tissue-specific gene expression. Nat Rev Genet 12, 283-293.

Orphanides, G., Lagrange, T., and Reinberg, D. (1996). The general transcription factors of RNA polymerase II. Genes Dev 10, 2657-2683.

Ouyang, J., and Gill, G. (2009). SUMO engages multiple corepressors to regulate chromatin structure and transcription. Epigenetics 4, 440-444.

Pare, A., Lemons, D., Kosman, D., Beaver, W., Freund, Y., and McGinnis, W. (2009). Visualization of individual Scr mRNAs during Drosophila embryogenesis yields evidence for transcriptional bursting. Curr Biol 19, 2037-2042.
Patikoglou, G., and Burley, S.K. (1997). Eukaryotic transcription factor-DNA complexes. Annu Rev Biophys Biomol Struct 26, 289-325.

Perry, M.W., Boettiger, A.N., Bothma, J.P., and Levine, M. (2010). Shadow enhancers foster robustness of Drosophila gastrulation. Curr Biol 20, 1562-1567.

Peterlin, B.M., and Price, D.H. (2006). Controlling the elongation phase of transcription with P-TEFb. Mol Cell 23, 297-305.

Peterson, C.L., and Workman, J.L. (2000). Promoter targeting and chromatin remodeling by the SWI/SNF complex. Curr Opin Genet Dev 10, 187-192.

Porcher, A., Abu-Arish, A., Huart, S., Roelens, B., Fradin, C., and Dostatni, N. (2010). The time to measure positional information: maternal hunchback is required for the synchrony of the Bicoid transcriptional response at the onset of zygotic transcription. Development 137, 2795-2804.

Porcher, A., and Dostatni, N. (2010). The bicoid morphogen system. Curr Biol 20, R249-R254.

Prives, C., and Manley, J.L. (2001). Why is p53 acetylated? Cell 107, 815-818.

Ptashne, M. (1988). How eukaryotic transcriptional activators work. Nature 335, 683-689.

Ptashne, M. (2004). Two "what if" experiments. Cell S116, S71-S72.

Ptashne, M., and Gann, A. (1997). Transcriptional activation by recruitment. Nature 386, 569-577.

Ptashne, M., and Gann, A. (1998). Imposing specificity by localization: mechanism and evolution. Curr Biol 8, R812-R822.

Ptashne, M., and Gann, A.A.F. (1990). Activators and targets. Nature 346, 329-331.

Ranish, J.A., and Hahn, S. (1996). Transcription: basal factors and activation. Curr Opin Genet Dev 6, 151-158.

Raser, J.M., and O'Shea, E.K. (2005). Noise in gene expression: origins, consequences, and control. Science (New York, NY 309, 2010-2013.

Rasmussen, E.B., and Lis, J.T. (1993). In vivo transcriptional pausing and cap formation on three Drosophila heat shock genes. Proc Natl Acad Sci USA 90, 7923-7927.

Rasmussen, E.B., and Lis, J.T. (1995). Short transcripts of the ternary complex provide insight into RNA polymerase II elongational pausing. J Mol Biol 252, 522-535.

Rougvie, A.E., and Lis, J.T. (1988). The RNA polymerase II molecule at the $5^{\prime}$-end of the uninduced hsp70 genes of $D$. melanogaster is transcriptionally engaged. Cell 54, 795-804.

Ruthenburg, A.J., Li, H., Patel, D.J., and Allis, C.D. (2007). Multivalent engagement of chromatin modifications by linked binding modules. Nat Rev Mol Cell Biol 8, 983-994.

Sadowski, I., Ma, J., Triezenberg, S., and Ptashne, M. (1988). GAL4VP16 is an unusually potent transcriptional activator. Nature 335 , 563-564.

Sharpe, J., Nonchev, S., Gould, A., Whiting, J., and Krumlauf, R. (1998). Selectivity, sharing and competitive interactions in the regulation of Hoxb genes. EMBO J 17, 1788-1798.

Sims, R.J. 3rd, Belotserkovskaya, R., and Reinberg, D. (2004a). Elongation by RNA polymerase II: the short and long of it. Genes Dev 18, 2437-2468.

Sims, R.J. 3rd, Mandal, S.S., and Reinberg, D. (2004b). Recent highlights of RNA-polymerase-II-mediated transcription. Curr Opin Cell Biol 16, 263-271. 
Spellman, P.T., and Rubin, G.M. (2002). Evidence for large domains of similarly expressed genes in the Drosophila genome. J Biol 1, 5 .

Spitz, F., Gonzalez, F., and Duboule, D. (2003). A global control region defines a chromosomal regulatory landscape containing the HoxD cluster. Cell 113, 405-417.

Stargell, L.A., and Struhl, K. (1996). Mechanisms of transcriptional activation in vivo: two steps forward. Trends Genet 12, 311-315.

Thanos, D., and Maniatis, T. (1995). Virus induction of human INF $\beta$ gene expression requires the assembly of an enhanceosome. Cell 83, 1091-1100.

To, T.L., and Maheshri, N. (2010). Noise can induce bimodality in positive transcriptional feedback loops without bistability. Science 327, 1142-1145.

Torigoi, E., Bennani-Baiti, I.M., Rosen, C., Gonzalez, K., Morcillo, P., Ptashne, M., and Dorsett, D. (2000). Chip interacts with diverse homeodomain proteins and potentiates bicoid activity in vivo. Proc Natl Acad Sci USA 97, 2686-2691.

Travers, A. (2000). Recognition of distorted DNA structures by HMG domains. Curr Opin Struct Biol 10, 102-109.

Triezenberg, S.J., Kingsbury, R.C., and McKnight, S.L. (1988). Functional dissection of VP16, the trans-activator of herpes simplex virus immediate early gene expression. Genes Dev 2, 718-729.

von der Lehr, N., Johansson, S., Wu, S., Bahram, F., Castell, A., Cetinkaya, C., Hydbring, P., Weidung, I., Nakayama, K., Nakayama, K.I., et al. (2003). The F-box protein Skp2 participates in c-Myc proteosomal degradation and acts as a cofactor for cMyc-regulated transcription. Mol Cell 11, 1189-1200.

Wallace, J.A., and Felsenfeld, G. (2007). We gather together: insulators and genome organization. Curr Opin Genet Dev 17, 400- 407.

Wang, W., Carey, M., and Gralla, J.D. (1992). Polymerase II promoter activation: Closed complex formation and ATP-driven start-site opening. Science 255, 450-453.

Wang, X., Muratani, M., Tansey, W.P., and Ptashne, M. (2010).
Proteolytic instability and the action of nonclassical transcriptional activators. Curr Biol 20, 868-871.

Weake, V.M., and Workman, J.L. (2010). Inducible gene expression: diverse regulatory mechanisms. Nat Rev Genet 11, 426-437.

West, A.G., Gaszner, M., and Felsenfeld, G. (2002). Insulators: many functions, many mechanisms. Genes Dev 16, 271-288.

Wu, C. (1997). Chromatin remodeling and the control of gene expression. J Biol Chem 272, 28171-28174.

Wu, J., and Grunstein, M. (2000). 25 years after the nucleosome model: chromatin modifications. Trends Biochem Sci 25, 619-623.

Wu, R.C., Feng, Q., Lonard, D.M., and O'Malley, B.W. (2007). SRC-3 coactivator functional lifetime is regulated by a phospho-dependent ubiquitin time clock. Cell 129, 1125-1140.

Wyrick, J.J., Holstege, F.C., Jennings, E.G., Causton, H.C., Shore, D., Grunstein, M., Lander, E.S., and Young, R.A. (1999). Chromosomal landscape of nucleosome-dependent gene expression and silencing in yeast. Nature 402, 418 421.

Xiao, H., Friesen, J.D., and Lis, J.T. (1995). Recruiting TATA-binding protein to a promoter: transcriptional activation without an upstream activator. Mol Cell Biol 15, 5757-5761.

Zeitlinger, J., Stark, A., Kellis, M., Hong, J.W., Nechaev, S., Adelman, K., Levine, M., and Young, R.A. (2007). RNA polymerase stalling at developmental control genes in the Drosophila melanogaster embryo. Nat Genet 39, 1512-1516.

Zhou, Q., Chen, D., Pierstorff, E., and Luo, K. (1998). Transcription elongation factor P-TEFb mediates Tat activation of HIV-1 transcription at multiple stages. EMBO J 17, 3681-3691.

Zhu, Y., Pe'ery, T., Peng, J., Ramanathan, Y., Marshall, N., Marshall, T., Amendt, B., Mathews, M.B., and Price, D.H. (1997). Transcription elongation factor P-TEFb is required for HIV-1 tat transactivation in vitro. Genes Dev 11, 2622-2632.

Zuniga, A., Michos, O., Spitz, F., Haramis, A.P., Panman, L., Galli, A., Vintersten, K., Klasen, C., Mansfield, W., Kuc, S., et al. (2004). Mouse limb deformity mutations disrupt a global control region within the large regulatory landscape required for Gremlin expression. Genes Dev 18, 1553-1564. 